\title{
Self-medication with antibiotics for the treatment of menstrual symptoms in southwest Nigeria: a cross-sectional study
}

\author{
Amy R Sapkota ${ }^{*}$, Morenike E Coker ${ }^{2}$, Rachel E Rosenberg Goldstein ${ }^{1}$, Nancy L Atkinson ${ }^{3}$, Shauna J Sweet ${ }^{1}$, \\ Priscilla O Sopeju², Modupe T Ojo ${ }^{4}$, Elizabeth Otivhia ${ }^{4}$, Olayemi O Ayepola ${ }^{5}$, Olufunmiso O Olajuyigbe ${ }^{6}$, \\ Laura Shireman ${ }^{7}$, Paul S Pottinger ${ }^{7}$, Kayode $\mathrm{K} \mathrm{Ojo}^{7}$
}

\begin{abstract}
Background: Self-medication with antibiotics is an important factor contributing to the development of bacterial antibiotic resistance. The purpose of this study was to evaluate the prevalence of self-medication with antibiotics for the treatment of menstrual symptoms among university women in Southwest Nigeria.

Methods: A cross-sectional survey was administered to female undergraduate and graduate students $(n=706)$ at four universities in Southwest Nigeria in 2008. The universities were selected by convenience and the study samples within each university were randomly selected cluster samples. The survey was self-administered and included questions pertaining to menstrual symptoms, analgesic and antibiotic use patterns, and demographics. Data were analyzed using descriptive statistics and logistic regression.

Results: The response rate was 95.4\%. Eighty-six percent (95\% Cl: 83-88\%) of participants experienced menstrual symptoms, and 39\% (95\% Cl: 36-43\%) reported using analgesics to treat them. Overall, 24\% (95\% Cl: 21-27\%) of participants reported self-medicated use of antibiotics to treat the following menstrual symptoms: cramps, bloating, heavy bleeding, headaches, pimples/acne, moodiness, tender breasts, backache, joint and muscle pain. Factors associated with this usage were: lower levels of education (Odds Ratio (OR): 2.8, 95\% Cl: 1.1-7.1, p-value: 0.03); nonscience major (OR: 1.58, 95\% Cl: 1.03-2.50, $p$-value: 0.04); usage of analgesics (OR: 3.17, 95\% Cl: 2.07-4.86, p-value: $<0.001$ ); and mild to extreme heavy bleeding (OR: 1.64, 95\% Cl: 1.01-2.67, p-value: 0.05) and pimples/acne (OR: 1.57, 95\% Cl: 0.98-2.54, $p$-value: 0.06). Ampicillin, tetracycline, ciprofloxacin and metronidazole were used to treat the most symptoms. Doctors or nurses (6\%, 95\% Cl: 4-7\%), friends (6\%, 95\% Cl: 4-7\%) and family members (7\%, 95\% Cl: $5-8 \%)$ were most likely to recommend the use of antibiotics for menstrual symptoms, while these drugs were most often obtained from local chemists or pharmacists (10.2\%, 95\% Cl: 8-12\%).

Conclusions: This is the first formal study to report that approximately 1 out of 4 university women surveyed in Southwest Nigeria self-medicate with antibiotics to treat menstrual symptoms. This practice could provide monthly, low-dose exposures to antibiotics among users. Further studies are necessary to evaluate the impacts of selfmedication on student health.
\end{abstract}

\section{Background}

Increasing rates of antimicrobial resistance have left clinicians with limited drug options for the treatment of bacterial infectious diseases. This is a major public health

\footnotetext{
* Correspondence: ars@umd.edu

'Maryland Institute for Applied Environmental Health, University of Maryland College Park, School of Public Health, College Park, MD, USA

Full list of author information is available at the end of the article
}

concern worldwide, especially in developing countries where higher rates of resistant bacterial infections persist $[1,2]$. For example, rates of multiple antibiotic resistance among urinary tract infection (UTI) bacterial isolates in Southwest Nigeria are significantly higher than that of any other country [3]. In addition, rates of other lifethreatening bacterial infections, such as communityacquired methicillin-resistant Staphylococcus aureus

\section{Biomed Central}


(MRSA), continue to rise in African countries including Nigeria [4] and Botswana [5]. Because the misuse and abuse of antibiotics is a major cause of antimicrobial resistance, research is needed to evaluate the specific antibiotic usage patterns that are prevalent in developing countries so that interventions can be developed and implemented. For such interventions to be effective, we must also understand the underlying socio-cultural factors that contribute to antimicrobial misuse and the subsequent amplification of resistance in human populations $[1,2]$.

In Nigeria, there are limited controls on the sale or advertisement of antimicrobials, creating opportunities for misinformation and misperceptions that can exacerbate improper antibiotic use $[1,6]$. In addition, counterfeit drugs and poor pharmaceutical qualities of available antimicrobials (containing no or substandard active ingredients) have been widely reported [7-9]. These factors often lead to higher rates of resistance to lessexpensive first-line regimens compelling subsequent changes in treatment protocols to include more expensive and sometimes more toxic drugs [10]. In addition, access to good and effective medical interventions is often limited due to poor hospital facilities; service fees; poverty and hunger; and illiteracy [1,2,6,11]. Patronage of "quacks," untrained individuals providing unconventional and unhygienic medical care, is therefore widespread and frequently becomes institutionalized as normal.

Within this paradigm, self-medication-previously defined by The World Health Organization [12]-is widely encouraged, even among educated elites, as a justification for preserving the scarce resources of trained physicians and other medical personnel [13]. Recent studies have sought to understand patterns of self-medication with antibiotics in developing and other countries [13-17]. These studies have identified several indications for self-medication with antibiotics including the common cold, [13,14,16] diarrhea or constipation, [15] and sore throat [16]. In a pilot survey that we conducted in July 2007 in Ago-Iwoye, Lagos, and Ibadan, Nigeria, we observed a disturbing new trend among university women of self-medication with antibiotics to treat menstrual symptoms [6]. In particular, participating women reported using antibiotics to reduce cramps, regulate heavy flow and prevent "infections" from feminine sanitary products [6]. However, comprehensive data regarding the magnitude of antibiotic self-medication for menstrual symptoms, the specific "other" menstrual symptoms that were being "treated," and the characteristics of the women who were more likely to self-medicate were not collected.

Therefore, the purpose of the present study was to determine the prevalence of self-medication with antibiotics for the treatment of menstrual symptoms among university women in Southwest Nigeria and to evaluate factors associated with this practice. Our pilot study [6] and a recent study conducted by Afolabi in Lagos State, Nigeria [18], informed the selection of factors evaluated in the present study.

\section{Methods}

\section{Survey Setting}

This study was carried out in February 2008 at four universities (two public and two private universities) located in Southwest Nigeria. The public universities were the University of Ibadan ( $>12,000$ total students) located in Oyo State and Obafemi Awolowo University (25,000 total students) located in Osun State. The private universities were Covenant University (6,000 total students) and Babcock University (6,000 total students), which are both located in Ogun State. These universities were selected via convenience sampling and were included in the study because students attending public versus private universities often represent different socioeconomic groups and we sought to evaluate whether socioeconomic status is one potential factor that influences the use of antibiotics for menstrual symptoms among university women.

The four universities included in the study account for $12 \%$ of the 34 operational universities in Southwest Nigeria which are comprised of 6 federally-funded universities, 10 state-funded universities, and 18 privatelyowned universities [19]. These 34 universities represent $33 \%$ of the total 104 Nigerian universities which are comprised of 27 federally-funded universities, 36 statefunded universities and 41 privately-owned universities throughout the country [20].

Approximately $69 \%$ of Nigerians complete primary school [21], and a World Bank report published in 2000 estimated that higher education in Nigeria only enrolls about $4 \%$ of the eligible age cohort [22]. A recent report described that the proportion of female students attending Nigerian higher institutions is rising to about $47 \%$ of overall students [19]. The proportion of female students at the universities included in this study was approximately $50 \%$.

\section{Sample size calculation}

A sample size calculation was performed using the following equation: $\mathrm{n}=\left(\mathrm{Z}^{2} P(1-P)\right) /\left(d^{2}\right)$, where $\mathrm{n}=$ sample size, $\mathrm{Z}=\mathrm{Z}$ statistic corresponding to a chosen level of confidence, $P=$ expected prevalence, and $d=$ precision [23]. In our calculation, we used $\mathrm{Z}=1.96, P=0.3$ and $d=0.05$. This calculation resulted in a sample size of 323. This sample size was doubled to account for the clustered nature of the study design [24,25], resulting in a sample size of 646 . To account for non-responses, 
researchers typically increase the calculated sample size by anywhere from 5 to $20 \%[24,25]$. We increased the sample size by $5 \%$ to account for non-responses, resulting in a sample size of 679 . However, to be more conservative, we cushioned our sample size by an additional (arbitrary) $\sim 10 \%$, arriving at a total sample size, $\mathrm{n}=740$. This total sample size was divided by the number of clusters (4 universities) included in the study to determine how many surveys should be administered at each university $[25,26]$. This method of dividing the sample equally among clusters was in accordance with "generic cluster sample" design methods previously described by the WHO Department of Vaccines and Biologicals [26].

\section{Sampling strategy}

At the University of Ibadan, Covenant University and Obafemi Awolowo University, study participants were recruited from residence halls. The sampling strategy at these universities was a three-stage cluster sampling plan. Female residence halls that housed both undergraduate and graduate students were randomly selected for inclusion in the study. Within the residence halls, blocks of rooms were then randomly selected for inclusion in the study and every resident of those rooms was invited to participate in the survey.

At Babcock University, study participants were recruited from lecture halls because we were ultimately not granted access to the residence halls at this university. Thus, at Babcock University, a one-stage cluster sampling strategy was employed. Lecture halls that housed both undergraduate and graduate classes were randomly selected for participation in the study and every female student within the randomly selected lecture halls was invited to participate in the study.

Institutional review board (IRB) approval was granted by the University of Maryland College Park IRB. Written informed consent was obtained from all study participants. No incentive was offered for completion of the survey.

\section{Survey Instrument}

Qualitative interviews conducted among twenty-seven young Nigerian women who anecdotally reported using antibiotics to normalize menstrual flow and treat discomfort associated with menstruation [6] informed the initial content and focus of the survey. A preliminary version of the survey was then piloted among a focus group of nine female instructors and students at the University of Ibadan to evaluate language, content, and sensitivity of the instrument [27]. Overall, focus group participants indicated that the survey was "good," "straight forward," and "important." However, focus group participants did suggest that a few minor language edits should be incorporated into the final survey.
These edits were incorporated and the revised survey instrument was also visually reformatted to improve flow and conceptual clarity [28].

The final survey instrument (Additional file 1) consisted of four sections containing both closed and openended questions. The first section included questions concerning menstrual periods, in particular pain and other symptoms experienced during menstruation. The second section consisted of questions relating to analgesics and antibiotics that women may have taken before, during, or after menstruation. The third section contained general demographic questions, and the fourth section consisted of detailed demographic questions relating to family status (e.g. single, married, etc.) and sexual activity. Responses to three questions in the second section (Questions 11, 12 and 13 shown in Additional file 1) were used to calculate the prevalence of recent antibiotic usage for menstrual symptoms. If a participant answered "Yes" to question 11 or checked off any box in questions 12 or 13, they were considered a "user" of antibiotics for the treatment of menstrual symptoms. "Self-medication" with antibiotics was verified using the participants qualitative answers to the open-ended question at the end of the questionnaire (Question 22 shown in Additional file 1).

\section{Administration of Survey Instrument}

At each university, the surveys were administered by our Nigerian collaborators, who are instructors, lecturers or affiliates at the participating universities. All survey administrators used the same script and study protocol to invite participants into the study, obtain informed consent, and administer the surveys.

\section{Statistical Analyses}

The survey data were checked, coded, and entered into a Microsoft Access database. The data were then cleaned and analyzed using descriptive and inferential statistics. Simple and multiple logistic regression models were used to evaluate associations between participant characteristics and reported usage of antibiotics to treat menstrual symptoms. All statistical analyses were carried out using Stata/IC 10 (StataCorp, College Station, Texas). Continuous data are presented as means, along with their 95\% confidence intervals (CIs).

\section{Results}

\section{Study population characteristics}

A total of 706 out of 740 administered surveys (95.4\% response rate) were completed and returned by female students attending Babcock University, Covenant University, University of Ibadan, and Obafemi Awolowo University. The characteristics of the study population are summarized in Table 1. 
Table 1 Study population $(n=706)$ characteristics

\begin{tabular}{|c|c|c|}
\hline Demographic Characteristics & $n$ & $\%$ \\
\hline \multicolumn{3}{|l|}{ University } \\
\hline Babcock University & 237 & 33.6 \\
\hline Covenant University & 167 & 23.7 \\
\hline University of Ibadan & 149 & 21.1 \\
\hline Obafemi Awolowo University & 153 & 21.7 \\
\hline \multicolumn{3}{|l|}{ Education Level } \\
\hline Preliminary level (Pre-college) & 3 & 0.42 \\
\hline Freshman (100 level) & 166 & 23.5 \\
\hline Sophomore (200 level) & 194 & 27.5 \\
\hline Junior (300 level) & 171 & 24.2 \\
\hline Senior (400 level) & 73 & 10.3 \\
\hline Final year of Pharmacy, Law, or Engineering & 45 & 6.4 \\
\hline Final year of Medical School & 2 & 0.3 \\
\hline Masters or Doctorate & 26 & 3.7 \\
\hline Missing data & 26 & 3.7 \\
\hline \multicolumn{3}{|l|}{ Area of Concentration } \\
\hline Lab Science, Medicine & 285 & 40.4 \\
\hline Social Sciences & 135 & 19.1 \\
\hline Humanities (Arts, Languages) & 97 & 13.7 \\
\hline Business and Finance & 102 & 14.5 \\
\hline Technology & 53 & 7.5 \\
\hline Missing data & 35 & 5.0 \\
\hline \multicolumn{3}{|l|}{$\overline{\text { Age }}$} \\
\hline$<17$ & 16 & 2.3 \\
\hline $17-20$ & 330 & 46.7 \\
\hline $21-24$ & 250 & 35.4 \\
\hline $25-29$ & 66 & 9.4 \\
\hline $30-34$ & 16 & 2.3 \\
\hline $35-39$ & 6 & 0.9 \\
\hline$\geq 40$ & 1 & 0.1 \\
\hline Missing data & 21 & 3.0 \\
\hline \multicolumn{3}{|l|}{ Marital Status } \\
\hline Single & 609 & 86.3 \\
\hline \multicolumn{3}{|l|}{ Engaged, Married, Separated, } \\
\hline Divorced or Widowed & 74 & 10.5 \\
\hline Missing data & 23 & 3.3 \\
\hline
\end{tabular}

\section{Menstruation}

The majority of study participants (88\%: $95 \% \mathrm{CI}, 86 \%$ to 91\%) reported experiencing three or four menstrual periods during the three-month time period that served as the focus for this study. Eighty-six percent (95\% CI: 83\% to $88 \%$ ) of participants reported experiencing pain or discomfort associated with their menstrual periods during this time frame. Yet, only $21 \%$ (95\% CI: $18 \%$ to $24 \%$ ) of study participants reported ever having seen a doctor or nurse for pain or discomfort associated with their menstrual periods. The specific types of pain or discomfort that were experienced included cramps; weight gain and water retention; heavy flow; headaches; pimples or acne; moodiness; tender or painful breasts; backache, joint or muscle pain; and other symptoms.

\section{Prevalence of self-medication}

When asked about the self-medicated use of analgesics and other pain-relieving medications, such as aspirin and ibuprofen, $39 \%$ (95\% CI: $36 \%$ to $43 \%$ ) of respondents reported that they had used these types of medications to treat menstrual symptoms in the past three months. The usage prevalence for these drugs was as follows: aspirin, $2 \%$ (95\% CI: $1 \%$ to 3\%); Panadol (paracetamol), 29\% (95\% CI: 26\% to 33\%); Panadol Extra (paracetamol and caffeine), 7\% (95\% CI: 5\% to 9\%); ibuprofen, $9 \%$ (95\% CI: $7 \%$ to $12 \%$ ); buscopan (butylscopolamine), $10 \%$ (95\% CI: $8 \%$ to $12 \%$ ); Feldene (piroxicam), $11 \%$ (95\% CI: $8 \%$ to $13 \%$ ); and other drugs, $11 \%(95 \%$ CI: $8 \%$ to $13 \%)$. These other drugs included, but were not limited to, codeine, Midol, Tylenol and Advil.

Overall, $24 \%$ (95\% CI: $21 \%$ to $27 \%$ ) of the study population reported self-medicating with antibiotics to treat menstrual symptoms in the past three months. The mean age when study participants first started taking antibiotics to treat menstrual symptoms was $15.7 \pm 2.96$ years. Interestingly, the prevalence of self-medicated antibiotic use for menstrual symptoms varied depending on education level (Table 2). In addition, individuals who were non-science majors were more likely to use antibiotics for menstrual symptoms compared with lab science, public health or medicine majors (Table 2, Figure 1). Study participants who used any pain-relieving medications (e.g. aspirin, ibuprofen) to treat menstrual symptoms were more likely to use antibiotics to treat menstrual symptoms than those who did not use any pain relievers (Table 2).

In terms of specific symptoms, those study participants who reported mild to severe heavy flow/heavy bleeding and mild to severe pimples/acne associated with menstruation were more likely to use antibiotics to treat these symptoms compared to individuals who reported experiencing no heavy flow/heavy bleeding or pimples/acne (Table 2). Surprisingly, women who reported mild to severe cramps were less likely to use antibiotics compared with those who reported experiencing no cramps (Table 2). Factors including age, specific university attended (hence, socio economic status), marital status, and sexual activity were not significantly associated with self-medicated use of antibiotics to treat menstrual symptoms.

\section{Types of antibiotics used}

Study participants reported using 12 antibiotics to treat a variety of symptoms before, during, and after menses. However, nearly all antibiotic users reported using only one antibiotic for the treatment of either one or more 
Table 2 Results of multivariate analysis of factors that may influence self-medication with antibiotics for the treatment of menstrual symptoms

\begin{tabular}{|c|c|c|c|}
\hline Independent Variable & Odds Ratio & 95\% Confidence Interval & $p$ - value \\
\hline \multicolumn{4}{|l|}{ Cramps } \\
\hline No $(n=187)$ & 1.00 & - & - \\
\hline Yes (Mild to severe) $(n=435)$ & 0.57 & $(0.36-0.91)$ & 0.02 \\
\hline \multicolumn{4}{|l|}{ Heavy flow/heavy bleeding } \\
\hline No $(n=186)$ & 1.00 & - & - \\
\hline Yes (Mild to severe) $(n=436)$ & 1.64 & $(1.01-2.67)$ & 0.05 \\
\hline \multicolumn{4}{|l|}{ Pimples/acne } \\
\hline No $(n=182)$ & 1.00 & - & - \\
\hline Yes (Mild to severe) $(n=456)$ & 1.57 & $(0.98-2.54)$ & 0.06 \\
\hline \multicolumn{4}{|l|}{ Education level } \\
\hline Preliminary and undergraduate levels $(n=607)$ & 1.00 & - & - \\
\hline Graduate level $(n=73)$ & 0.36 & $(0.14-0.91)$ & 0.03 \\
\hline \multicolumn{4}{|l|}{ Major } \\
\hline Lab science, public health or medicine $(n=285)$ & 1.00 & - & - \\
\hline Non-science $(n=386)$ & 1.58 & $(1.03-2.50)$ & 0.04 \\
\hline \multicolumn{4}{|l|}{ Use of pain relievers to relieve menses symptoms } \\
\hline No $(n=411)$ & 1.00 & - & - \\
\hline Yes $(n=276)$ & 3.17 & $(2.07-4.86)$ & $<0.001$ \\
\hline \multicolumn{4}{|l|}{ Age } \\
\hline$\leq 20(n=346)$ & 1.00 & - & - \\
\hline $21-29(n=316)$ & 1.09 & $(0.68-1.74)$ & 0.72 \\
\hline$\geq 30(n=23)$ & 1.78 & $(0.31-10.1)$ & 0.52 \\
\hline \multicolumn{4}{|l|}{ University } \\
\hline Babcock University $(\mathrm{n}=237)$ & 1.00 & - & - \\
\hline Covenant University $(n=167)$ & 1.13 & $(0.62-2.07)$ & 0.68 \\
\hline University of Ibadan ( $\mathrm{n}=149$ ) & 1.61 & $(0.90-2.88)$ & 0.10 \\
\hline Obafemi Awolowo University $(n=153)$ & 1.26 & $(0.69-2.28)$ & 0.45 \\
\hline
\end{tabular}

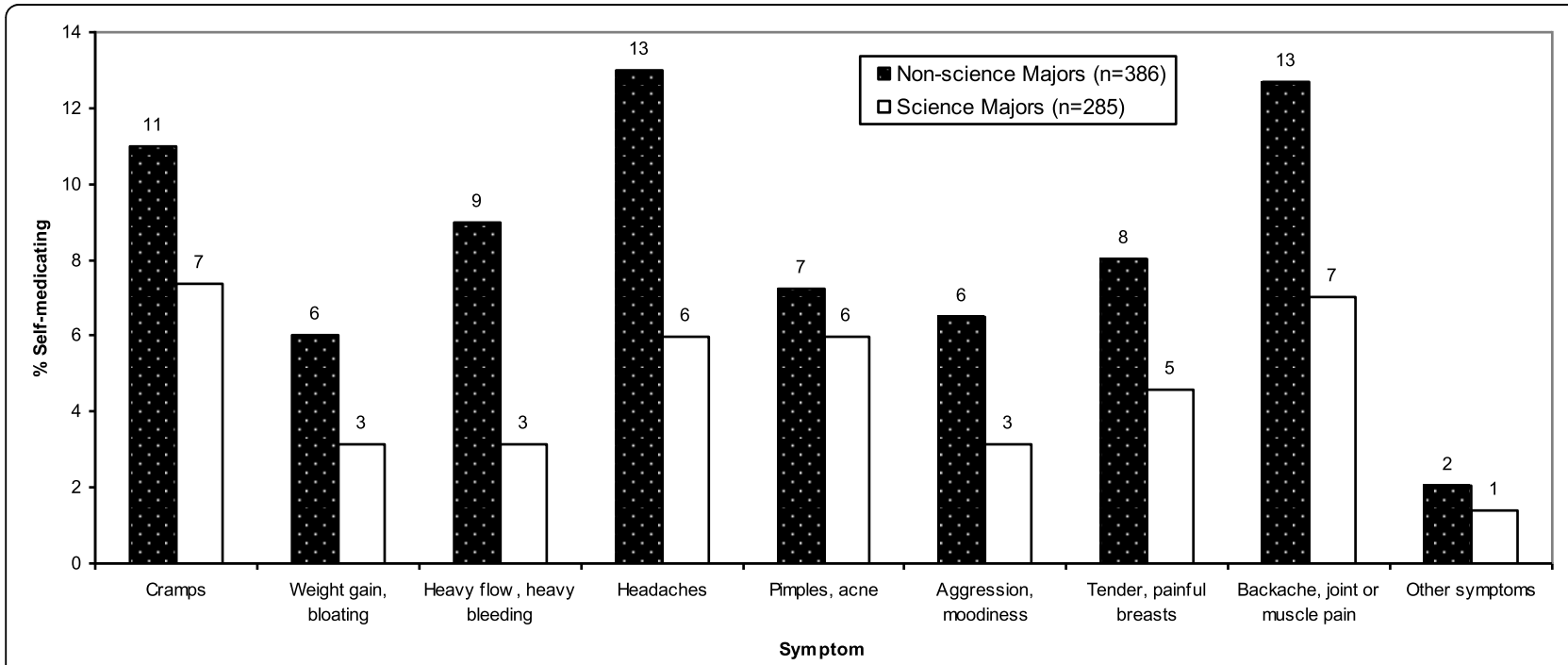

Figure 1 Prevalence of self-medication with antibiotics for the treatment of menstrual symptoms among University women in Southwest Nigeria by major area of study and symptoms. 
Table 3 Number of study participants using specific antibiotics to treat specific menstrual symptoms (n, (\%, 95\% confidence interval)), and estimates of the overall prevalence of use for each antibiotic for one or more menstrual symptoms $(\%, 95 \%$ confidence interval)

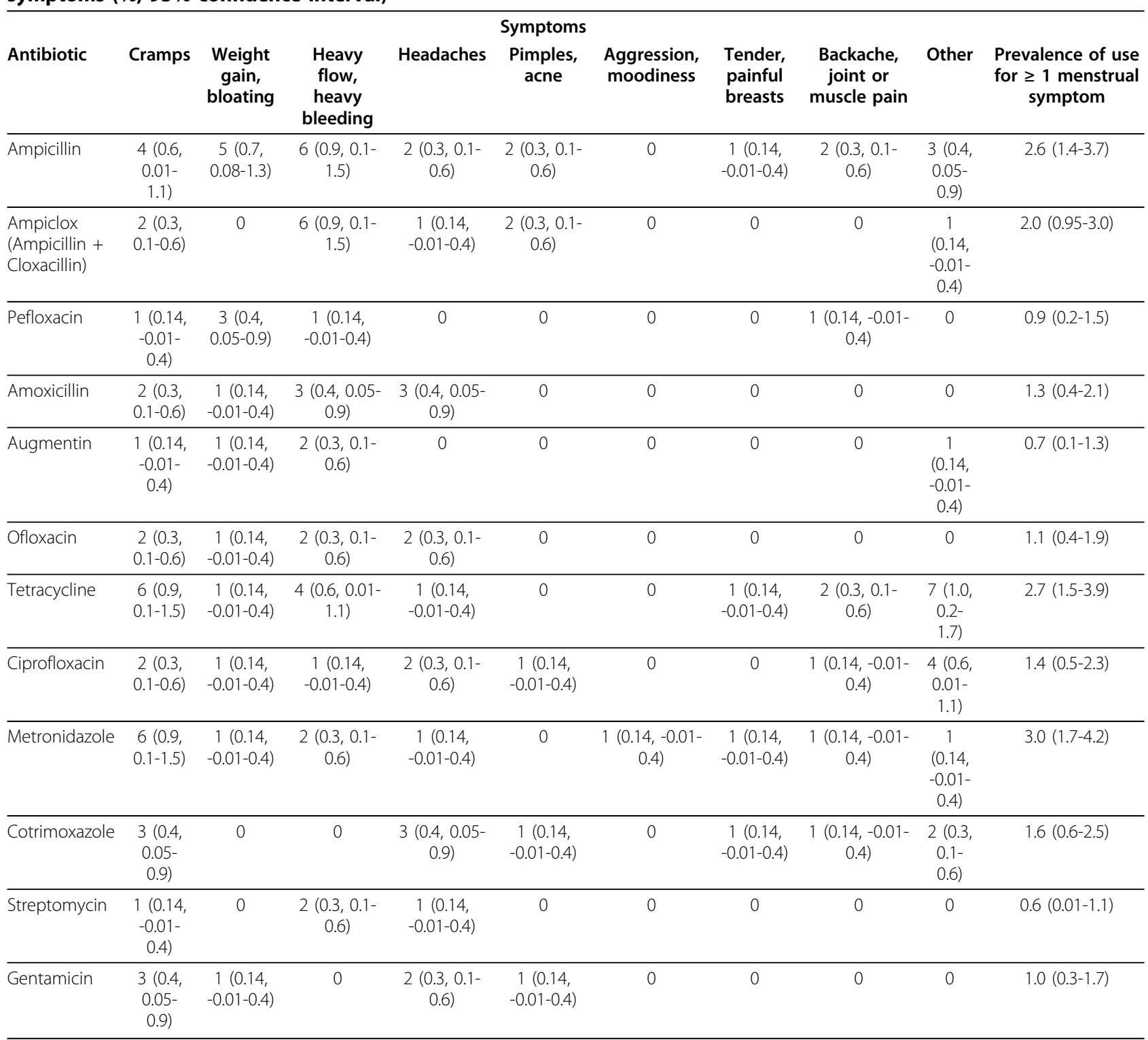

specific symptoms during the 3 -month period that served as the focus for the survey. Table 3 summarizes the types of antibiotics that were used to treat specific menstrual symptoms and provides estimates of the prevalence of use for each antibiotic. Ampicillin, tetracycline, ciprofloxacin and metronidazole were used to treat the most menstrual symptoms ( $\geq 7$ symptoms). If a preferred antibiotic was not available, 8\% (95\% CI: 6\% to $10 \%$ ) of study participants reported that they would use another type of antibiotic to treat the specific menstrual symptom. When asked whether these antibiotics were effective in relieving symptoms, a number of participants reported that the drugs relieved each of the symptoms, of which the largest proportions indicated that antibiotics relieved backache, joint or muscle pain (10\%, $95 \%$ CI: $8 \%$ to $12 \%)$, headaches $(10 \%, 95 \%$ CI: $8 \%$ to $12 \%)$, and cramps $(9 \%, 95 \% \mathrm{CI}: 6 \%$ to $11 \%)$.

\section{Sources of information and antibiotics}

Study participants also reported that a variety of individuals first recommended that they take antibiotics to treat menstrual symptoms. Doctors or nurses $(6 \%, 95 \%$ CI: $4 \%$ to $7 \%)$, friends $(6 \%, 95 \% \mathrm{CI}: 4 \%$ to $7 \%)$ and family members $(7 \%, 95 \% \mathrm{CI}$ : $5 \%$ to $8 \%)$ were the individuals who were most often cited as recommending antibiotics for these symptoms (Figure 2). However, the 


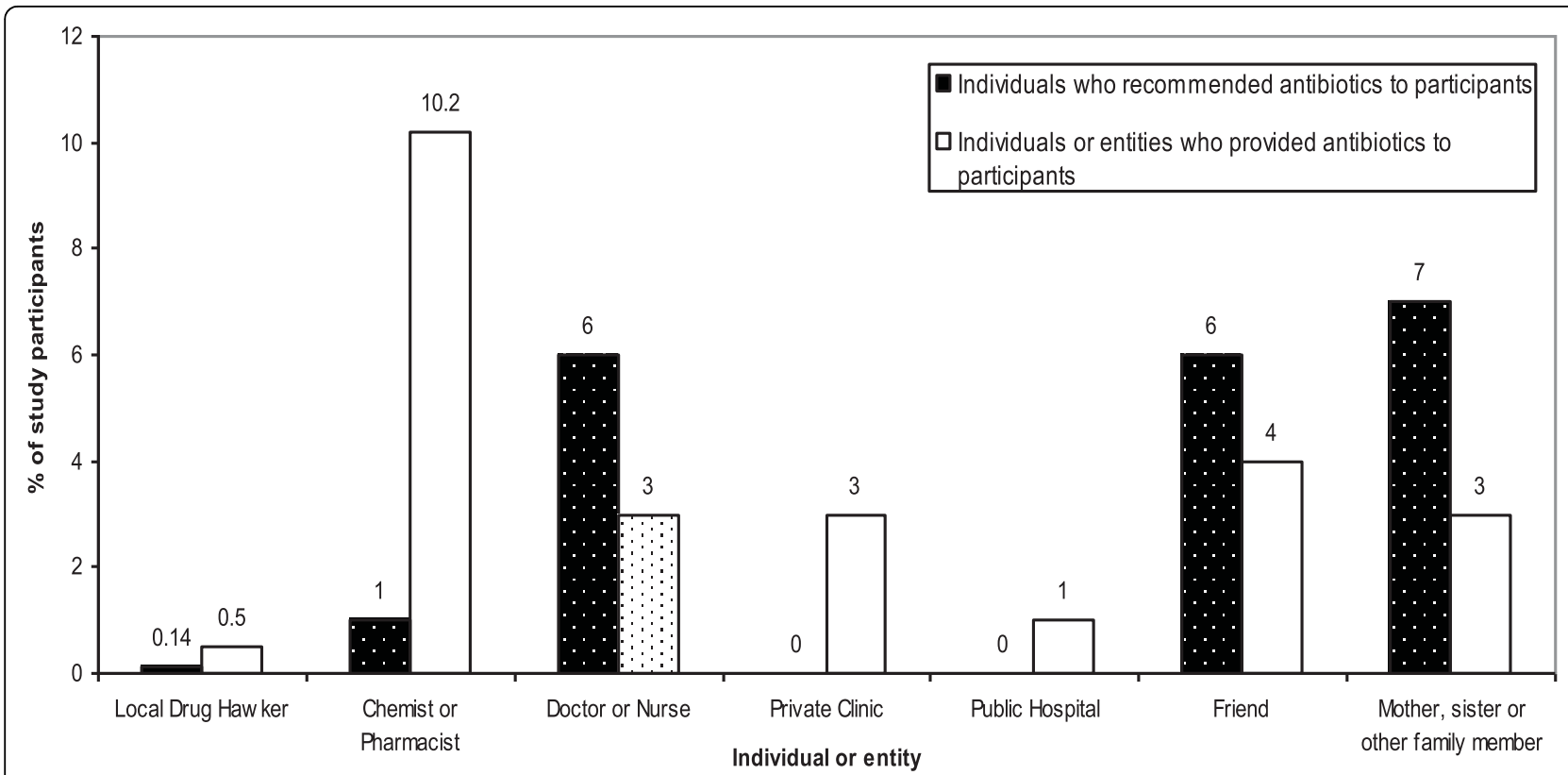

Figure 2 Individuals who recommended the use of antibiotics to treat menstrual symptoms and individuals or entities who provided antibiotics to study participants.

antibiotics used to treat menstrual symptoms were most often obtained from local chemists or pharmacists (10.2\%, 95\% CI: $8 \%$ to $12 \%$ ) (Figure 2).

\section{Discussion}

In this study, we identified that approximately 1 out of 4 surveyed female university students in Southwest Nigeria practiced self-medication with antibiotics to treat a variety of menstrual symptoms. Ampicillin, tetracycline, ciprofloxacin and metronidazole were used to treat the most menstrual symptoms, and the drugs were most often obtained from local chemists or pharmacists. To our knowledge, this is the first formal study to report such a high rate of antibiotic self-medication among women of child-bearing age in Southwest Nigeria.

These results are potentially more alarming compared with other unorthodox, self-medicated uses of antibiotics because the menstrual cycle occurs monthly. While we did not collect data concerning the frequency of selfmedication with antibiotics for the treatment of menstrual symptoms, we speculate that the use of antibiotics for menstrual symptoms that may last only a few days every month could possibly provide frequent, low-dose exposures among users. Low doses of antibiotics on a regular basis may expose the normal gut bacterial florawhich can cause UTIs-to sub-inhibitory doses that favor the selection of resistant bacteria. A previous study in Southwest Nigeria identified a high prevalence of UTIs among women of child-bearing age [29], and other studies have shown that the prevalence of multiple resistance to commonly-used antibiotics among UTI bacterial isolates from Southwest Nigeria is considerably higher than that of any other part of the world [3,30-32]. Thus, it is possible that the self-medication behaviors that we have identified among young women in this study may be contributing to the elevated rates of antibiotic-resistant UTIs that have been documented in this region.

However, additional studies are necessary to identify whether the antibiotic self-medication practices described here are also prevalent among Nigerian women who do not attend college. The young women surveyed in this study represent a small, elite proportion of the female, Nigerian population [21]. Thus, it is unclear whether the responses of the surveyed women are representative of other women in Southwest Nigeria (and beyond) who do not attend college. Similarly, at this time, it is difficult to estimate 1) the overall magnitude of the antibiotic selective pressures; and 2) the specific subsequent effects on bacterial antibiotic resistance that are associated with self-medicated antibiotic usage for the treatment of menstrual symptoms in Nigeria.

While the present study was the first formal study to assess self-medication with antibiotics for menstrual symptoms among university women in Southwest Nigeria, another recent study identified antibiotic use for menstrual symptoms among secondary school girls in Osun State (the location of one of our participating universities) [33]. In this study, Ogunfowokan and 
Babatunde (2010) described that $1 \%$ of secondary school girls reported using tetracycline for the management of menstrual pain [33]. This is similar to our finding that $2.7 \%$ of our study participants specifically used tetracycline to treat several menstrual symptoms including cramps, and heavy flow (Table 3). However, since Ogunfowokan and Babatunde (2010) used a survey with openended questions on the self-management of menstrual symptoms and tetracycline was noted as the only cited antibiotic, the overall prevalence of antibiotic use for the treatment of menstrual symptoms is likely lower in the Ogunfowokan and Babatunde (2010) study compared to the present study.

Beyond self-medicated use of antibiotics for menstrual symptoms, other studies have evaluated antibiotic selfmedication patterns, in general, among other populations in Nigeria indicating that this overall practice is common. For example, Afolabi et al. (2010) recently identified that $30.4 \%$ of surveyed dental patients in Ondo State- which is also located in Southwest Nigeria-practiced self-medication with antibiotics [34]. In another recent study, Afolabi (2008) assessed factors that are associated with self-medication, in general, among market women (mostly of the Yoruba ethnic group) in Lagos State, located in Southwest Nigeria [18]. In this study, level of education was identified as a major factor that influenced self-medication patterns, while age was not significantly associated with self-medication [18]. These data are similar to our findings that show that higher levels of education are inversely associated with self-medicated antibiotic use for menstrual symptoms (Table 2), while age and socio-economic status are not significantly associated with this type of antibiotic usage. In contrast, Afolabi (2008) identified that market women most often obtained their information about medications, as well as the medications themselves, from patent medicine stores, while the present study found that information about antibiotic usage and the antibiotics themselves were most often obtained from family members and local chemists or pharmacists, respectively. Previous studies conducted in Africa have also identified pharmacies as important sources of selfadministered drugs $[17,35]$.

Understanding the sources of information and sources of drugs for antibiotic self-medication can help in the formulation of community-based interventions that can help to reduce self-medication practices. Our data suggest that interventions are indicated at several levels: public health education directed at populations, and medical education directed at health professionals. Since girls are more likely to receive information about menstruation and other health issues from their mothers, other female relatives and friends rather than through formal education sources $[36,37]$, providing health education on the appropriate use of antibiotics to female family members in the general population may be more productive initially than educating university or school girls directly.

Medical education efforts also are indicated since our findings show that clinicians are likely to recommend and pharmacists are likely to provide antimicrobials for menstrual problems. These efforts could be directed at medical and other health profession students who are at the initial stages of their medical education, as well as practicing physicians, and other healthcare professionals. Encouragingly, we found that students who studied medicine and public health were less likely to misuse antibiotics for menstrual complaints compared to nonscience majors. This suggests that those women who are currently studying disciplines related to healthcare fields could positively impact the individuals whom they treat in the future with regard to potential reductions in selfmedication practices [15].

This is a cross-sectional study that utilized a selfadministered survey to estimate the prevalence of selfmedicated antibiotic use in the past. Therefore, by design, recall bias cannot be ruled out. In addition, since the survey was self-administered, respondents may have skipped questions that they did not understand. Moreover, respondents may have underreported antibiotic usage because issues related with menses are culturally sensitive and often viewed as a taboo subject. Respondents also might not have known what an antibiotic is; although this may be less of an issue particularly among our survey respondents since they were all university students. The fact that surveys were administered in residence halls or lecture halls depending on the university is also a limitation. However, the data show that survey administration in either residence halls or lecture halls was not a factor that influenced the findings.

Another limitation of the study is that, while random sampling was completed at each university, the universities themselves were selected by convenience. In a study of this type, we did not have the ability to randomly select a sample of all Nigerian universities for inclusion in the study because we did not have the luxury of having collaborators present at every Nigerian university who could complete the necessary field work. As a result, it is unclear whether our findings are generalizable to other Nigerian universities.

\section{Conclusions}

In summation, our findings provide the first prevalence data on self-medication with antibiotics for the treatment of menstrual symptoms among young Nigerian university women. We speculate that this type of practice could provide monthly, low-dose exposures to antibiotics among users, and could partially explain the high 
rates of antibiotic-resistant UTIs previously described in Nigeria.

By targeting educated women of child-bearing age, this study addresses a population with more resources than the general population. Future research should be expanded to include other populations of Nigerian women to determine the overall prevalence of self-medicated antibiotic use for menstrual symptoms in the country, as well as any additional knowledge deficits and attitudinal barriers to eliminating antimicrobial misuse. Such information could then be used to develop education initiatives and theory-based behavior modification programs directed at reducing the misuse of antibiotics among women and their healthcare providers in Nigeria.

\section{Additional material}

Additional file 1: Women's Health and Health Behaviors Survey. The survey instrument used in the study entitled, "Self-medication with antibiotics for the treatment of menstrual symptoms in southwest Nigeria: a cross-sectional study."

\section{Acknowledgements}

We thank Erin J. Engelson and Erinna L. Kinney for helpful suggestions in the conception and design of the study. This work was supported by a startup package provided by the University of Maryland College Park, School of Public Health to A.R.S. The funder played no role in the study design; collection and analysis of data; manuscript preparation; and decision to publish the manuscript.

\section{Author details}

1 Maryland Institute for Applied Environmental Health, University of Maryland College Park, School of Public Health, College Park, MD, USA. ${ }^{2}$ University of Ibadan, Ibadan, Oyo State, Nigeria. ${ }^{3}$ Department of Public and Community Health, University of Maryland College Park, School of Public Health, College Park, MD, USA. ${ }^{4}$ Olabisi Onabanjo University, Ago-Iwoye, Ogun State, Nigeria. ${ }^{5}$ Covenant University, Ota, Ogun State, Nigeria. ${ }^{6}$ Babcock University, Ikeja, Ogun State, Nigeria. ${ }^{7}$ University of Washington, Seattle, WA, USA.

\section{Authors' contributions}

ARS conceived, designed and supervised the study; performed the data analysis; and led the writing. MOC helped in the design of the study and study instrument; conducted focus groups; analyzed focus group data; administered surveys at University of Ibadan; and revised the manuscript. RERG played a major role in data cleaning, data input, and data analysis; and drafted sections of the manuscript. NLA contributed to the data analysis and interpretation; and contributed to a section of the manuscript. SJW played a major role in the design and flow of the study instrument; performed power calculations; designed the study sampling protocol; and revised the manuscript. POS conducted focus groups; helped in the analysis of focus group data and reworking of the survey instrument; administered surveys at University of Ibadan; and revised the manuscript. MTO conducted focus groups; helped in the analysis of focus group data and reworking of the survey instrument; administered surveys at Obafemi Awolowo University: and revised the manuscript. EO conducted focus groups and helped to analyze focus group data; administered surveys at Obafemi Awolowo University; and revised the manuscript. OOA conducted focus groups: helped in the analysis of focus group data and reworking of the survey instrument; administered surveys at Covenant University; and revised the manuscript. $\mathrm{OOO}$ helped in the design of the study; led the logistical nightmare of getting the surveys to Nigeria and then back to the U.S.; administered surveys at Babcock University; and revised the manuscript. LS developed the Access database; performed descriptive statistics; and drafted and revised the manuscript. PSP performed data analysis; and revised the manuscript. KKO organized and conceived the entire collaboration; conceived, designed and supervised the study; and participated in the writing. All authors read and approved the final manuscript.

\section{Competing interests}

The authors declare that they have no competing interests.

Received: 29 March 2010 Accepted: 15 October 2010

Published: 15 October 2010

\section{References}

1. Okeke IN, Aboderin OA, Byarugaba DK, Ojo KK, Opintan JA: Growing problem of multidrug-resistant enteric pathogens in Africa. Emerging Infectious Diseases 2007, 13:1640-1646.

2. Ojo KK, Sapkota AR, Ojo TB, Pottinger PS: Antimicrobial resistance gene distribution: A socioeconomic and sociocultural perspective. GMS German Medical Science - an Interdisciplinary Journal 2008, 3:Doc 26.

3. Aboderin OA, Abdu A, Odetoyin BW, Lamikanra A: Antimicrobial resistance in Escherichia coli strains from urinary tract infections. Journal of the national medical association 2009, 101:1268-1273.

4. Ghebremedhin B, Olugbosi MO, Raji AM, Layer F, Bakare RA, Konig B, et al: Emergence of a community-associated methicillin-resistant Staphylococcus aureus strain with a unique resistance profile in Southwest Nigeria. J Clin Microbiol 2009, 47:2975-2980.

5. Wood SM, Shah SS, Bafana M, Ratner AJ, Meaney PA, Malefho KC, et al: Epidemiology of methicillin-resistant Staphylococcus aureus bacteremia in Gaborone, Botswana. Infect Control Hosp Epidemiol 2009, 30:782-785.

6. Ojo KK, Sapkota A: Self-prescribed use of antimicrobials during menstrual periods: a disturbing new example of information poverty in Nigeria. Journal of Infection in Developing Countries 2007, 1:123-124.

7. Okeke IN, Lamikanra A: Quality and bioavailability of tetracycline capsules in a Nigerian semiurban community. International Journal of Antimicrobial Agents 1995, 5:245-250

8. Nkang AO, Okonko IO, Lennox JA, Babalola ET, Adewale OG, Motayo BO, et al: Survey of the efficacy and quality of some brands of the antibiotics sold in Calabar Metropolis, South-south region of Nigeria. Scientific Research and Essays 2010, 5:395-406.

9. Okeke IN, Lamikanra A: Quality and bioavailability of ampicillin capsules dispensed in a Nigerian semi-urban community. Afr J Med Med Sci 2001, 30:47-51.

10. Okeke IN, Ojo KK: Antimicrobial use and resistance in Africa. In Antimicrobial Resistance in Developing Countries. Edited by: Sosa A, Byarugaba DK, Amábile-Cuevas CF, Hsueh PR, Kariuki S, Okeke IN. New York: Springer; 2009:301-314

11. Shankar PR, Partha P, Shenoy N: Self-medication and non-doctor prescription practices in Pokhara valley, Western Nepal: a questionnairebased study. BMC Fam Pract 2002, 3:17.

12. World Health Organization: Guideline for the regulatory assessment of Medicinal Products for use in self-medication. WHO/EDM/OSM?00.1 2000

13. Saradamma RD, Higginbotham N, Nichter M: Social factors influencing the acquisition of antibiotics without prescription in Kerala State, south India. Social Science \& Medicine 2000, 50:891-903.

14. Buke C, Hosgor-Limoncu M, Ermertcan S, Ciceklioglu M, Tuncel M, Kose T, et al: Irrational use of antibiotics among university students. Journal of Infection 2005, 51:135-139.

15. Sawalha AF: Self-medication with antibiotics: A study in Palestine. The International Journal of Risk and Safety in Medicine 2008, 20:213-222.

16. Borg MA, Scicluna EA: Over-the-counter acquisition of antibiotics in the Maltese general population. Int J Antimicrob Agents 2002, 20:253-257.

17. Awad A, Eltayeb I, Matowe L, Thalib L: Self-medication with Antibiotics and Antimalarials in the community of Khartoum State, Sudan. Journal of Pharmacy and Pharmaceutical Sciences 2005, 8:326-331.

18. Afolabi AO: Factors influencing the pattern of self-medication in an adult Nigerian population. Ann Afr Med 2008, 7:120-127.

19. Olugbile $S$ : Varsity enrollment: Females improve in male-dominated courses. Lagos, Nigeria, Punch Nigeria Limited 2010 [http://www.punchng. com/Articl.aspx?theartic=Art2010010510202167].

20. National University Commission (NUC): List of Nigerian Universities and Years founded. 2010 [http://www.nuc.edu.ng/pages/universities.asp]. 
21. Saint W, Hartnett TA, Strassner E: Higher education in Nigeria: a status report. Higher Education Policy 2003, 16:259-281.

22. Task Force on Higher Education and Society: Higher Education in Developing Countries: Peril and Promise. World Bank, Washington, DC 2000, 20433[http://siteresources.worldbank.org/EDUCATION/Resources/ 278200-1099079877269/547664-1099079956815/peril_promise_en.pdf].

23. Daniel WW: Biostatistics: A Foundation for Analysis in the Health Sciences New York: John Wiley \& Sons, Incorporated, 71998.

24. Naing L, Winn T, Rusli BN: Practical issues in calculating the sample size for prevalence studies. Archives of Orofacial Sciences 2006, 1:9-14.

25. UN International Fund for Agricultural Development (IFAD): Calculating the sample size. 2010 [http://www.ifad.org/gender/tools/hfs/anthropometry/ ant_3.htm], 9-20-2010.

26. Hoshaw-Woodard S: Description and comparison of the methods of cluster sampling and lot quality assurance sampling to assess immunization coverage. WHON\&B/01.26 Geneva, The Department of Vaccines and Biologicals. World Health Organization 2001.

27. Morgan DL: Focus groups. Annual Review of Sociology 1996, 22:129-152.

28. Christian LM, Dillman DA: The influence of graphical and symbolic language manipulations on responses to self-administered questions. Public Opinion Quarterly 2004, 68:57-80.

29. Okonko IO, ljandipe LA, Ilusanya OA, Donbraye-Emmanuel OB, Ejembi J, Udeze $A O$, et al: Incidence of urinary tract infection (UTI) among pregnant women in Ibadan, South-Western Nigeria. African Journal of Biotechnology 2009, 8:6649-6657.

30. Soge OO, Queenan AM, Ojo KK, Adeniyi BA, Roberts MC: CTX-M-15 extended-spectrum beta-lactamase from Nigerian Klebsiella pneumoniae. Journal of Antimicrobial Chemotherapy 2006, 57:24-30.

31. Ojo KK, Kehrenberg C, Odelola HA, Schwarz S, Roberts MC: Tetracycline resistant plasmids from uropathogenic Escherichia coli from southwestern Nigeria. Journal of Chemotherapy 2006, 18:112-114.

32. Oni AA, Okesola AO: Antimicrobial resistance among common bacterial pathogens in south western Nigeria. American-Eurasian Journal of Agricultural \& Environmental Sci 2009, 5:327-330.

33. Ogunfowokan AA, Babatunde OA: Management of primary dysmenorrhea by school adolescents in ILE-IFE, Nigeria. J Sch Nurs 2010, 26:131-136.

34. Afolabi AO, Akinmoladun VI, Adebose IJ, Elekwachi G: Self-medication profile of dental patients in Ondo State, Nigeria. Niger J Med 2010, 19:96-103

35. Joubert PH, Sebata PD, van Reenen OR: Self-medication in a developing community. S Afr Med J 1984, 65:129-131.

36. Umeora OUJ, Egwuatu VE: Menstruation in rural Igbo women of south east Nigeria: attitudes, beliefs and practices. African Journal of Reproductive Health 2008, 12:109-115.

37. Adinma ED, Adinma JID: Perceptions and practices on menstruation amongst Nigerian secondary school girls. African Journal of Reproductive Health 2008, 12:74-83.

\section{Pre-publication history}

The pre-publication history for this paper can be accessed here:

http://www.biomedcentral.com/1471-2458/10/610/prepub

\section{doi:10.1186/1471-2458-10-610}

Cite this article as: Sapkota et al: Self-medication with antibiotics for the treatment of menstrual symptoms in southwest Nigeria: a crosssectional study. BMC Public Health 2010 10:610.

\section{Submit your next manuscript to BioMed Central and take full advantage of:}

- Convenient online submission

- Thorough peer review

- No space constraints or color figure charges

- Immediate publication on acceptance

- Inclusion in PubMed, CAS, Scopus and Google Scholar

- Research which is freely available for redistribution

Submit your manuscript at www.biomedcentral.com/submit
C Biomed Central 